\title{
Putative cancer-initiating stem cells in cell culture models for molecular subtypes of clinical breast cancer
}

\author{
NITIN TELANG \\ Cancer Prevention Research Program, Palindrome Liaisons Consultants, Montvale, NJ 07645-1559, USA
}

Received April 30, 2015; Accepted September 9, 2015

DOI: $10.3892 / 01.2015 .3780$

\begin{abstract}
Cancer-initiating stem cells (CISC) represent a minor subpopulation of heterogeneous breast cancer. CISC are responsible for the acquired resistance to conventional chemoendocrine therapy and eventual relapse observed in patients with breast cancer. Certain molecular subtypes of clinical breast cancer that exhibit differential expression of genes coding for hormone and growth factor receptors differ in their response to conventional chemoendocrine therapy and targeted therapeutic inhibitors. Thus, the development of reliable cell culture models for CISC may provide a valuable experimental approach for the study of stem cell-targeted therapy for the treatment of breast cancer. The present study utilized optimized cell culture systems as experimental models for different molecular subtypes of clinical breast cancer, including luminal A, human epidermal growth factor receptor (HER)-2-enriched and triple negative breast cancer. Biomarker end points, including control of homeostatic growth, cancer risk and drug resistance, were quantitatively analyzed in the selected models. The results of the analyses indicated that, compared with the non-tumorigenic controls, the cell models representing the aforementioned molecular subtypes of clinical breast cancer exhibited aberrant cell cycle progression, downregulated cellular apoptosis and loss of control of homeostatic growth, as evidenced by hyperproliferation. Additionally, these models displayed persistent cancer risk, as indicated by their high incidence and frequency of anchorage-independent (AI) colony formation in vitro and their tumor development capacity in vivo. Furthermore, in the presence of maximum cytostatic drug concentrations, the drug-resistant phenotypes isolated from the parental drug-sensitive cell lines representing luminal A, HER-2-enriched and triple negative breast cancer exhibited an 11.5, 5.0 and 6.2 fold increase in cell growth, and a 5.6, 5.4 and 4.4 fold increase in the number of AI colonies, respectively, compared with the drug-sensitive controls.
\end{abstract}

Correspondence to: Dr Nitin Telang, Cancer Prevention Research Program, Palindrome Liaisons Consultants, 10 Rolling Ridge Road, Suite B, Montvale, NJ 07645-1559, USA

E-mail: entitytoo@gmail.com or ntelang3@gmail.com

Key words: cancer stem cell models, breast cancer
Collectively, the data of the present study demonstrated the presence of putative CISC in these breast cancer models.

\section{Introduction}

Cancer-initiating stem cells (CISC) represent a minor cell subpopulation of heterogeneous breast cancer. CISC are characterized by a unique self-renewal program, enhanced tumorigenic potential and resistance to conventional therapeutic interventions (1-4). Thus, reliable cell culture models for clinical CISC may constitute useful experimental approaches for the development of novel cancer stem cell-targeted therapies for the treatment of chemoendocrine therapy-resistant clinical breast cancer.

Gene expression profiling has facilitated the use of targeted therapy for the treatment of certain molecular subtypes of breast cancer that differ in the expression of hormone and/or growth factor receptors, including luminal $\mathrm{A}$ and $\mathrm{B}$, human epidermal growth factor receptor (HER)-2-enriched, triple negative (basal-like) and normal-like breast cancer (5). However, the long-term use of small molecule inhibitor-based targeted chemoendocrine therapy is frequently associated with de novo or acquired tumor resistance, which compromises the therapeutic efficacy of the treatment and promotes the progression of therapy-resistant disease in patients affected by these molecular subtypes of breast cancer (6-9). Therapy-resistant CISC are considered to be responsible for the progression of metastatic disease $(2,4)$. Therefore, experimental approaches that enable the isolation and characterization of putative CISC are essential for the identification of promising stem cell-targeted therapeutic lead compounds. Several in vitro and in vivo assays have been previously optimized for the isolation and characterization of putative CISC, which are specific for the following cell populations: i) Drug efflux positive side populations; ii) drug-resistant phenotypes; iii) phenotypes expressing signature cellular markers, including cluster of differentiation (CD)44, CD24 and aldehyde dehydrogenase (ALDH); iv) phenotypes expressing signature nuclear transcription factors such as octamer-binding transcription factor 4 (Oct-4), homeobox transcription factor NANOG and c-Myc; v) phenotypes able to form non-adherent tumor spheroids in vitro; and vi) phenotypes with enhanced in vivo tumorigenic potential (10-12).

The aim of the present study was to establish reliable cell culture models for several molecular subtypes of breast 
cancer, in addition to demonstrating the efficacy of prototypic chemoendocrine therapeutic agents on the established cell models, and isolating putative CISC from these models.

The results demonstrated that the cell models employed in the present study, which represent different molecular subtypes of clinical breast cancer (namely luminal A, HER-2-enriched and triple negative breast cancer), exhibited loss of control of normal homeostatic growth, retention of cancer risk and sensitivity to growth inhibition by prototypic chemoendocrine therapeutic agents. Furthermore, the drug-resistant phenotypes isolated from the aforementioned breast cancer models displayed persistent cell proliferation in the presence of high doses of chemotherapeutic agents, suggesting the presence of putative CISC in these models.

\section{Materials and methods}

Experimental models. The human breast carcinoma-derived cell line Michigan Cancer Foundation (MCF)-7 (estrogen receptor $(\mathrm{ER})^{+}$, progesterone receptor $(\mathrm{PR})^{+}$and HER-2-) (Michigan Cancer Foundation, Detroit, MI, USA), the HER-2-transfectant tumorigenic mammary epithelial cell line 184-B5/HER (ER-, PR- and HER-2 ${ }^{+}$) (Professor CW Welsch; Michigan State University, East Lansing, MI, USA) and the breast adenocarcinoma cell line MDA-MB-231 (ER ${ }^{-}, \mathrm{PR}^{-}$and HER-2) (American Type Culture Collection, Manassas, VA, USA) were selected as representative models for three molecular subtypes of clinical breast cancer, namely luminal A, HER-2-enriched and triple negative breast cancer, respectively. The 184-B5 cell line (Professor CW Welsch; Michigan State University) was used as the control. The cell lines were cultured in Dulbecco's modified Eagle medium (DMEM)/F-12 (Sigma-Aldrich, St. Louis, MO, USA) supplemented with $10 \%$ serum (Gibco; Thermo Fisher Scientific, Waltham, MA, USA), $240 \mathrm{IU} / \mathrm{ml}$ insulin (Eli Lilly \& Co., Indianapolis, IA, USA), $1 \mu \mathrm{M}$ dexamethasone (Sigma-Aldrich), $10 \mathrm{ng} / \mathrm{ml}$ epidermal growth factor, $0.5 \mu \mathrm{g} / \mathrm{ml}$ hydrocortisone and $10 \mu \mathrm{g} / \mathrm{ml}$ transferrin (all obtained from Sigma-Aldrich). A total of $1.0 \times 10^{5}$ cells were seeded, incubated at $37^{\circ} \mathrm{C}$ in a humidified atmosphere with $5 \% \mathrm{CO}_{2}$, and routinely subcultured at a 1:4 ratio when the culture reached $\sim 70-80 \%$ confluency (13-15).

Growth assays. Population doubling time, saturation density, cell cycle progression, cellular apoptosis, anchorage-independent (AI) colony formation and tumorigenic potential were evaluated on the aforementioned cell lines, following previously published protocols (14-18). Population doubling times were determined from the number of viable cells counted every $24 \mathrm{~h}$ during the exponential growth phase of the cell culture, which lasted 7 days. For the saturation density assay, $1.0 \times 10^{5}$ cells were seeded, and the number of viable cells counted 7 days later was considered to represent the saturation density. The viable cell number for population doubling and saturation density was determined via trypan blue exclusion test (Sigma-Aldrich) using a hemocytometer (Sigma-Aldrich) (14-18). Cell cycle progression and cellular apoptosis were determined by flow cytometry analysis of cells at $G_{1}, S, G_{2} / M$ and sub $G_{0}$ phases of the cell cycle. Briefly, cells were stained with $50 \mu \mathrm{g}$ the propidium iodide (Calbiochem, La Jolla, CA, USA) and sorted using the EPICS 752 flow cytometer (Beckman Coulter, Miami, FL, USA). The data from the cell cycle phase distribution was analyzed using the multi-cycle MPLUS software (Phoenix Flow Systems, San Diego, CA, USA) following published protocols $(14,15)$. The data were represented as $\mathrm{G}_{1}: \mathrm{S}+\mathrm{G}_{2} / \mathrm{M}$ and $\mathrm{S}+\mathrm{G}_{2} / \mathrm{M}$ :sub $\mathrm{G}_{0}$ ratios. These ratios provided information about the relative proportion of quiescent vs. proliferative cells, and proliferative vs. apoptotic cells, respectively. To evaluate the capacity of the different cell lines to form AI colonies, 1,000 cells/well were seeded, and subsequently the cells were suspended in $0.33 \%$ soft agar, overlaid on a $0.6 \%$-agar basement matrix, and maintained in culture for 21 days. AI colony formation was then determined by the number of AI colonies derived from these cells. The in vivo tumorigenic potential of the different cell lines was determined following subcutaneous transplantation of $1.0 \times 10^{6}$ cells, suspended in $0.2 \mathrm{ml}$ phosphate-buffered saline, in 6-8 week old female BALB/c athymic 'nude' mice (Charles River Laboratories, Newark, DE, USA). The mice were sacrificed by $\mathrm{CO}_{2}$ asphyxiation, 3-5 weeks following transplantation when the tumors had reached a diameter of $1 \mathrm{~cm}$. The data were presented as tumor incidence and latency rates.

Chemotherapeutic agents. The selective ER modulator tamoxifen (TAM), the synthetic retinoid 4-(hydroxyphenyl) retinamide (4-HPR) and the anthracycline doxorubicin (DOX; all obtained from Sigma-Aldrich) were selected as test compounds, based on their efficacy as clinical chemoendocrine therapeutic agents (6-8). Stock solutions of these agents at $100 \mathrm{mM}$ concentration were prepared by dissolving the drugs in $100 \%$ ethanol (Thermo Fisher Scientific). In order to obtain pharmacologically relevant final concentrations of these compounds, the stock solutions were serially diluted in the culture medium. Dose response experiments, performed within the pharmacologically achievable ranges, identified the values corresponding to the inhibitory concentration (IC) $)_{50}$ and $\mathrm{IC}_{90}$ for these drugs. The $\mathrm{IC}_{90}$ represented the maximum cytostatic dose, which was defined as the highest concentration of the test compound that resulted in a number of viable cells equal to or greater than the initial seeding density.

Drug-resistant phenotype. The drug-resistant phenotypes were isolated from the cell subpopulation that survived and exhibited progressive growth in the presence of a concentration of the corresponding chemoendocrine therapeutic agent equivalent to its $\mathrm{IC}_{90}$. This surviving population was expanded in the presence of high doses of the corresponding chemoendocrine therapeutic drug for a minimum of five passages prior to the experiments.

Statistical analysis. Cell culture experiments were performed in duplicate ( $\mathrm{N}=6 /$ treatment group), while AI colony formation experiments were performed in triplicate ( $\mathrm{N}=18 /$ treatment group). Cell culture data are presented as the mean \pm SD. In vivo transplantation experiments were performed using $10 \mathrm{mice} / \mathrm{cell}$ line. Statistically significant differences between the control and the experimental data points were assessed by two-sample t-test, using GraphPad Prism software, version 5.0 (GraphPad Software Inc., La 
Table I. Loss of control of homeostatic growth in cell culture models representing different molecular subtypes of clinical breast cancer.

Cell culture model

Biomarker end point

184-B5 MCF-7 $184-$ B 5 / H E R

MDA-MB-231

Population doubling time $(\mathrm{h})^{\mathrm{a}}$

Saturation density $\left(\mathrm{x} 10^{5} \text { cells }\right)^{\mathrm{b}}$

$\mathrm{G}_{1}: \mathrm{S}+\mathrm{G}_{2} / \mathrm{M}$ ratio $^{\mathrm{c}}$

$\mathrm{S}+\mathrm{G}_{2} / \mathrm{M}$ :sub $\mathrm{G}_{0}$ ratio $^{\mathrm{c}}$

$\begin{array}{cc}34.0 & 15.2 \\ 22.3 \pm 1.2 & 26.6 \pm 1.7 \\ 2.3 \pm 0.4 & 1.4 \pm 0.2 \\ 1.6 \pm 0.3 & 12.8 \pm 2.4\end{array}$

$12.8 \pm 2.4$
15.0

$32.8 \pm 1.5$

$0.8 \pm 0.1$

$10.8 \pm 1.6$
15.0

$32.9 \pm 2.3$

$0.6 \pm 0.3$

$16.8 \pm 3.2$

${ }^{\mathrm{a}}$, determined from the exponential growth phase of the cell culture; ${ }^{\mathrm{b}}$, determined at day 7 post-seeding of $1.0 \times 10^{5}$ cells. Data represent the mean $\pm \mathrm{SD}\left(\mathrm{N}=6 /\right.$ treatment group); ${ }^{\mathrm{c}}$, determined from cell cycle analysis by flow cytometry. Data represent the mean $\pm \mathrm{SD}(\mathrm{N}=3 /$ treatment group. MCF-7, Michigan Cancer Foundation-7; HER, human epidermal growth factor receptor. Data has been published previously $(17,19)$.

Table II. Gain of cancer risk in cell culture models representing different molecular subtypes of clinical breast cancer.

Cell culture model

\begin{tabular}{lcccc}
\cline { 2 - 3 } Biomarker end point & 184-B5 & MCF-7 & 184-B5/HER & MDA-MB-231 \\
\hline AI colony formation & & & \\
Incidence & $0 / 18$ & $18 / 18$ & $18 / 18$ & $18 / 18$ \\
Mean colony number & - & $30.9 \pm 2.4$ & $23.0 \pm 2.6$ & $38.9 \pm 1.6$ \\
Tumor formation $^{\mathrm{b}}$ & $0 / 10$ & $10 / 10$ & $10 / 10$ & $10 / 10$ \\
Incidence $_{\text {Latency (weeks) }}^{24}$ & $3-5$ & $3-5$ & $3-5$ \\
\hline
\end{tabular}

${ }^{\text {a }}$, AI colonies counted at day 21 post-seeding of 1,000 cells. Data represent the mean $\pm \mathrm{SD}(\mathrm{N}=18 /$ treatment group $)$; ${ }^{\mathrm{b}}$, palpable tumors following subcutaneous transplantation; AI, anchorage-independent; MCF-7, Michigan Cancer Foundation-7; HER, human epidermal growth factor receptor. Data has been published previously $(17,19)$.

Jolla, CA, USA). P<0.05 was considered to indicate a statistically significant difference.

\section{Results}

Status of homeostatic growth control and cancer risk. The data summarized in Table I $(17,19)$ compare the values obtained for a series of quantitative biomarker end points measured in non-tumorigenic 184-B5 cells vs. breast cancer-derived MCF-7, 184-B5/HER and MDA-MB-231 cells. The tumorigenic cells exhibited a $\geq 55 \%$ reduction in population doubling time, $19-47 \%$ increase in saturation density, $39-74 \%$ reduction in the $G_{1}: S+G_{2} / M$ ratio and 7.0-9.5 fold increase in the $S+G_{2} / M: s u b G_{0}$ ratio. Additionally, unlike the non-tumorigenic 184-B5 cells, the tumorigenic cells exhibited AI growth in vitro and retained their tumor development ability in vivo (Table II) $(17,19)$.

Drug-resistant CISC. The data presented in Fig. 1A summarize the results of the dose response experiment performed with TAM in MCF-7 cells, which identified the $\mathrm{IC}_{50}$ and $\mathrm{IC}_{90}$ for $\mathrm{TAM}$ as $94.30 \mathrm{nM}$ and $1.25 \mu \mathrm{M}$, respectively. The data presented in Fig. 1B compare the survival rate of
TAM-sensitive (TAM-S) vs. TAM-resistant (TAM-R) MCF-7 cells in the presence of a concentration of TAM equivalent to its $\mathrm{IC}_{90}$. The number of viable cells treated with TAM was $2.0 \pm 1.0 \times 10^{5}$ cells in the TAM-S group, vs. $25.0 \pm 1.5 \times 10^{5}$ cells in the TAM-R group. Thus, compared with the TAM-S phenotype, the TAM-R phenotype exhibited an 11.5 fold higher number of viable cells $(\mathrm{P}=0.001)$.

The data presented in Fig. 2A summarize the results of the dose response experiment conducted with 4-HPR in 184-B5/HER cells. This experiment identified the $\mathrm{IC}_{50}$ and $\mathrm{IC}_{90}$ for $4-\mathrm{HPR}$ as 0.31 and $0.49 \mu \mathrm{M}$, respectively. The data presented in Fig. 2B compare the survival rate of 4-HPR-sensitive (4-HPR-S) vs. 4-HPR-resistant (4-HPR-R) 184-B5/HER cells in the presence of a concentration of 4-HPR equivalent to its $\mathrm{IC}_{90}$. The number of viable cells in the 4-HPR-treated 4-HPR-S group was $4.0 \pm 2.0 \times 10^{5}$ cells, while in the 4-HPR-treated 4-HPR-R group the number of viable cells was $24.0 \pm 1.1 \times 10^{5}$ cells. Therefore, the $4-H P R-R$ cells exhibited a 5 fold higher number of viable cells, compared with the 4-HPR-S cells $(\mathrm{P}=0.02)$.

The data presented in Fig. 3A summarize the results from the dose response experiment performed with DOX in MDA-MB-231 cells, wherein 0.2 and $0.5 \mu \mathrm{M}$ were identified 
A

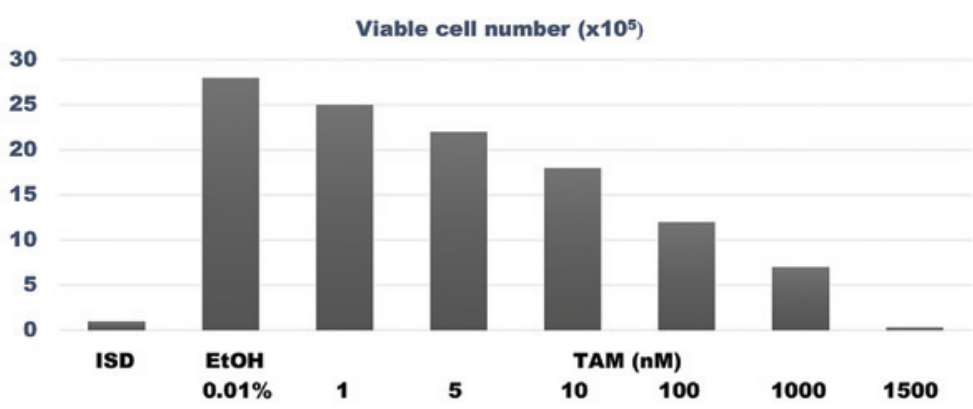

B

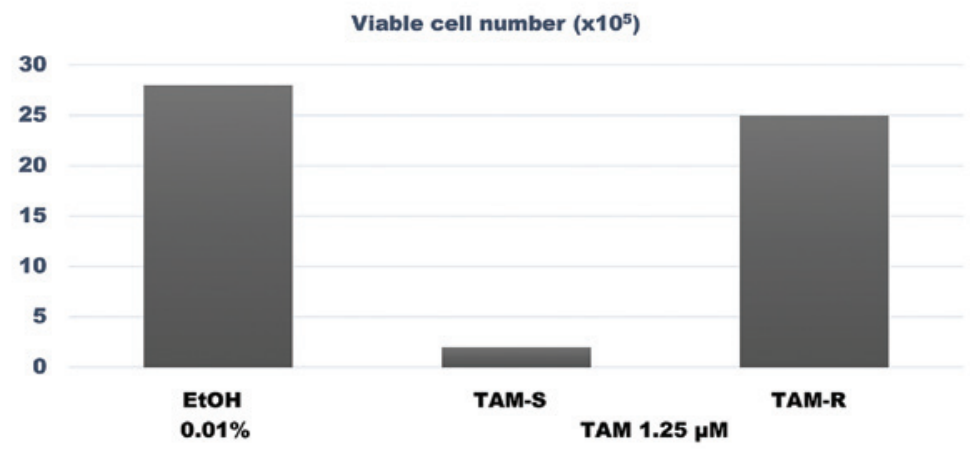

Figure 1. (A) Dose response of TAM on MCF-7 cells. $\mathrm{IC}_{50}=94.3 \mathrm{nM} ; \mathrm{IC}_{90}=1.25 \mu \mathrm{M}$. (B) Isolation of TAM-R phenotype. In the presence of a concentration of TAM equivalent to its $\mathrm{IC}_{90}$, the number of viable MCF-7 cells presenting TAM-R phenotype was 11.5 fold higher than those displaying TAM-S phenotype. Data represent the mean $\pm \mathrm{SD}$ ( $\mathrm{N}=6 /$ treatment group; $\mathrm{P}=0.001$ vs. control). TAM, tamoxifen; MCF-7, Michigan Cancer Foundation-7; IC, inhibitory concentration; TAM-R, TAM-resistant; TAM-S, TAM-sensitive; ISD, initial seeding density; EtOH, ethanol.

A

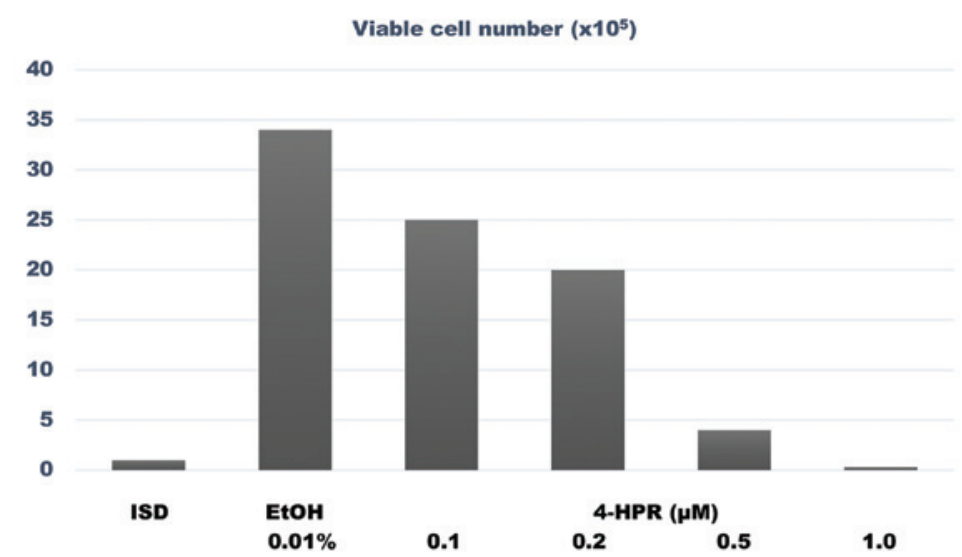

$\mathbf{B}$

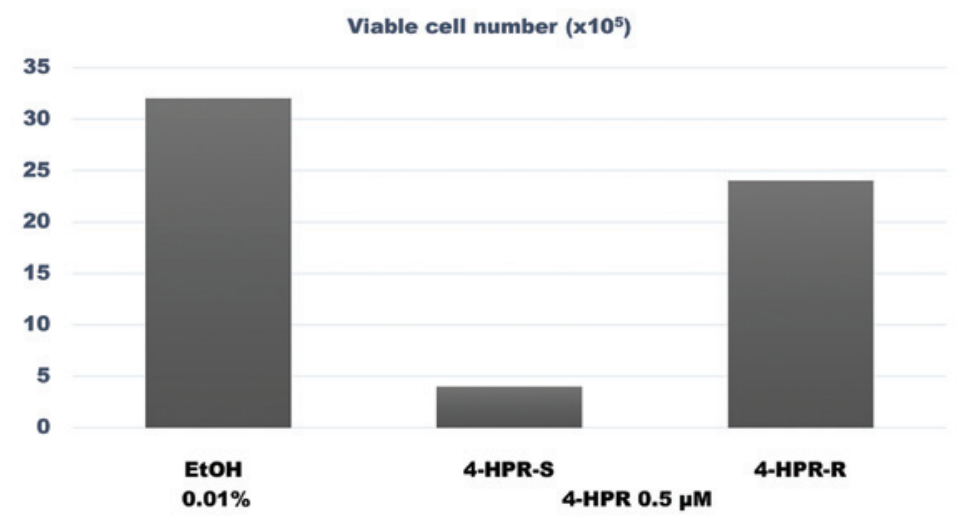

Figure 2. (A) Dose response of 4-HPR on 184-B5/HER cells. $\mathrm{IC}_{50}=0.31 \mu \mathrm{M} ; \mathrm{IC}_{90}=0.49 \mu \mathrm{M}$. (B) Isolation of 4-HPR-R phenotype. In the presence of a concentration of 4-HPR equivalent to its $\mathrm{IC}_{90}$, the 4-HPR-R phenotype exhibited a 5.0 fold higher number of viable cells than the 4-HPR-S phenotype. Data represent the mean $\pm \mathrm{SD}(\mathrm{N}=6 /$ treatment group; $\mathrm{P}=0.02$ vs. control). 4-HPR, 4-(hydroxyphenyl) retinamide; HER, human epidermal growth factor receptor; IC, inhibitory concentration; 4-HPR-R, 4-HPR-resistant; 4-HPR-S, 4-HPR-sensitive; ISD, initial seeding density; EtOH, ethanol. 
A

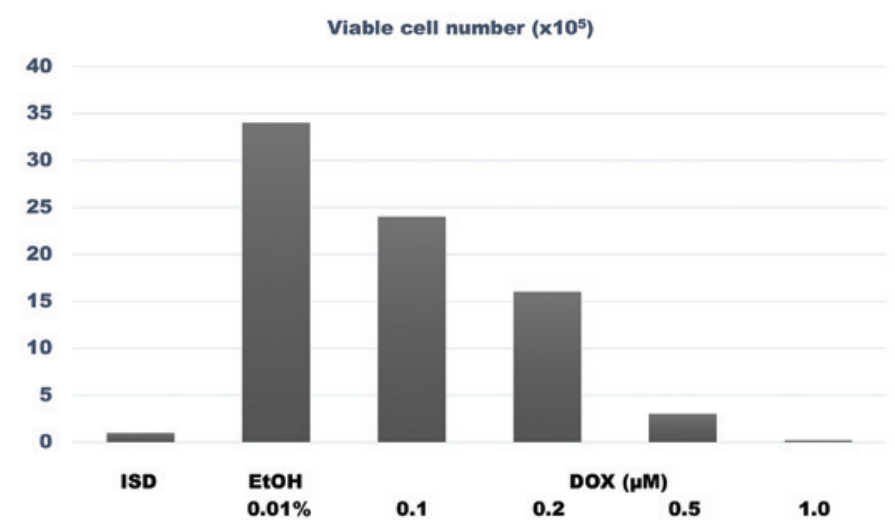

B

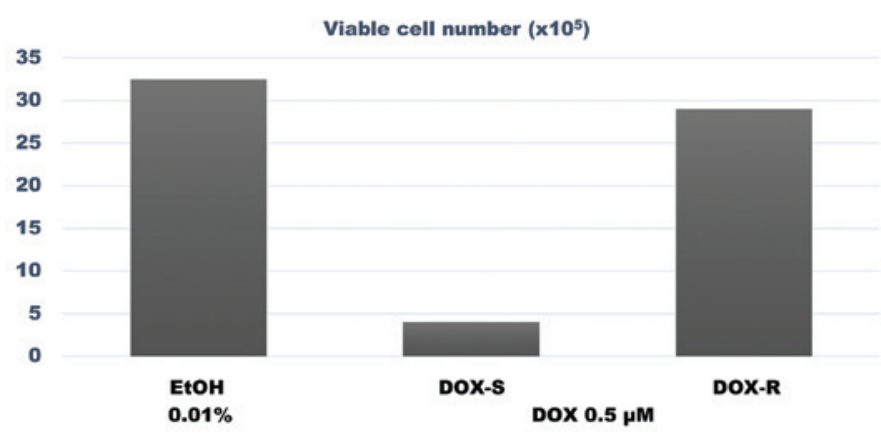

Figure 3. (A) Dose response of DOX on MDA-MB-231 cells. $\mathrm{IC}_{50}=0.2 \mu \mathrm{M} ; \mathrm{IC}_{90}=0.5 \mu \mathrm{M}$. (B) Isolation of DOX-R phenotype. The DOX-R phenotype exhibited a 6.2 fold higher number of viable cells than the DOX-S phenotype in the presence of a concentration of DOX equivalent to its IC ${ }_{90}$. Data represent the mean $\pm \mathrm{SD}$ ( $\mathrm{N}=6 /$ treatment group; $\mathrm{P}=0.02$ vs. control). DOX, doxorubicin; IC, inhibitory concentration; DOX-R, DOX-resistant; DOX-S, DOX-sensitive; ISD, initial seeding density; EtOH, ethanol.

Table III. Anchorage-independent colony formation in drug-resistant phenotypes.

\begin{tabular}{|c|c|c|c|}
\hline \multirow[b]{2}{*}{ Chemotherapy status } & \multicolumn{3}{|c|}{ Anchorage-independent colony number ${ }^{\mathrm{a}}$} \\
\hline & MCF-7 & 184-B5/HER & MDA-MB-231 \\
\hline Drug-sensitive $^{\mathrm{b}}$ & $3.8 \pm 1.4$ & $3.5 \pm 0.9$ & $4.1 \pm 1.1$ \\
\hline Drug-resistant ${ }^{\mathrm{b}}$ & $25.3 \pm 2.5$ & $22.3 \pm 2.5$ & $22.1 \pm 1.8$ \\
\hline Increase (fold) & 5.6 & 5.4 & 4.4 \\
\hline
\end{tabular}

as the $\mathrm{IC}_{50}$ and $\mathrm{IC}_{90}$ of DOX, respectively. The data presented in Fig. 3B compare the survival ability of DOX-sensitive (DOX-S) vs. DOX-resistant (DOX-R) MDA-MB-231 cells in the presence of a concentration of DOX equivalent to its $\mathrm{IC}_{90}$. The number of viable cells among the DOX-treated DOX-S cells was $4.0 \pm 2.2 \times 10^{5}$ cells, vs. $29.0 \pm 2.0 \times 10^{5}$ cells among the DOX-treated DOX-R cells. Thus, the DOX-R cells exhibited a 6.2 fold higher number of viable cells, compared with the DOX-S cells $(\mathrm{P}=0.02)$.

The data presented in Table III summarize the results of the AI growth assay conducted to compare the AI growth of drug-sensitive vs. drug-resistant phenotypes in the presence of maximum cytostatic concentrations of the corresponding chemotherapeutic agent. The results demonstrated that the TAM-R, 4-HPR-R and DOX-R phenotypes, which were seeded at an initial cell density $\leq 10$ fold lower than that of their corresponding parental cell lines, exhibited a $5.6(\mathrm{P}=0.02)$, $5.4(\mathrm{P}=0.02)$ and $4.4(\mathrm{P}=0.03)$ fold increase in the number of AI colonies, respectively, compared with the drug-sensitive controls.

\section{Discussion}

The aim of the present study was to develop reliable cell culture models for putative CISC in three molecular subtypes of clinical breast cancer, namely luminal A, HER-2-enriched and 
triple negative breast cancer. The results of the experiments conducted to determine the status of homeostatic growth control and cancer risk in the cell culture models for the aforementioned molecular subtypes of clinical breast cancer indicated that, compared with the non-tumorigenic triple negative 184-B5 cells, the tumorigenic $\mathrm{ER}^{+} / \mathrm{PR}^{+} / \mathrm{HER} 2$ - luminal A, ER $/ \mathrm{PR}^{-} / \mathrm{HER}-2^{+}$HER-2-enriched and ER $/ \mathrm{PR}^{-} / \mathrm{HER}^{-}{ }^{-}$triple negative cell culture models exhibited hyperproliferation, aberrant cell cycle progression and downregulated cellular apoptosis. Taken together, these data suggest that the breast carcinoma-derived cell culture models used in the present study had lost control of their normal homeostatic growth, as evidenced by hyperproliferation, aberrant cell cycle progression and downregulated cellular apoptosis. These findings are consistent with those previously reported in the literature (13-18,20). In addition, contrary to the non-tumorigenic control cells, the breast carcinoma-derived cells appeared to have retained an enhanced risk for tumor development, as indicated by their ability to exhibit AI growth in vitro and tumor development in vivo following subcutaneous transplantation. Thus, AI growth represents a specific and sensitive in vitro surrogate biomarker for cancer risk (13,17-20).

Previous studies on luminal A, HER-2-enriched and triple negative models of breast cancer have demonstrated that hyperproliferation and cancer risk are reduced in these cell models by several mechanistically distinct pharmacological agents and naturally occurring dietary components, demonstrating the susceptibility of these models to effective chemopreventive or therapeutic treatment options (13-18). These aspects prompted the application of cell culture models for the characterization of CISC in the different molecular subtypes of breast cancer analyzed in the present study.

Phenotypic resistance to chemoendocrine therapy has been effectively used for the isolation of putative drug-resistant CISC $(2,4,10-12)$. In the present study, the experiments designed to isolate drug-resistant phenotypes from the models for luminal A, HER-2-enriched and triple negative breast cancer utilized TAM, 4-HPR and DOX, respectively, for the selective expansion of the resistant phenotypes, since these agents have been used for the clinical management of the aforementioned molecular subtypes of breast cancer (6-8). The data derived from these experiments clearly demonstrated persistent growth of drug-resistant cells in the presence of maximum cytostatic concentrations of the corresponding chemotherapeutic agents, thereby providing experimental evidence for the potential clinical translatability of the in vitro data obtained in the present study. Furthermore, the status of cellular markers specific for stem cells, including CD44, CD24 and ALDH, and nuclear transcription factors such as Oct-4, NANOG and c-Myc (10-12), may provide a robust characterization of the putative drug-resistant phenotypes isolated from the breast cancer models used in the present study.

Targeted therapy for luminal A, HER-2-enriched and triple negative breast cancer, includes selective ER modulators and aromatase inhibitors, HER-2-targeted small molecule inhibitors and poly (ADP-ribose) polymerase inhibitors, respectively (21-24). However, these treatment options are frequently associated with de novo or acquired tumor drug resistance, which has been attributed to the upregulation of survival pathways associated with the overexpression of phosphoinositide
3-kinase/Akt/mammalian target of rapamycin; the upregulation of proliferativepathwaysassociated with the overexpression of rat sarcoma/rapidly accelerated fibrosarcoma/mitogen-activated protein kinases-extracellular signal-regulated kinase; and the downregulation of apoptotic pathways associated with the modulation of the expression of anti- or pro-apoptotic proteins in the aforementioned molecular subtypes of breast cancer $(2,9,22,23,25,26)$. Thus, the analysis of the expression levels of molecules that have been previously documented to be associated with survival, proliferative and apoptotic pathways in putative CISC is likely to further aid in the characterization of CISC phenotypes.

Long-term chemoendocrine therapy is frequently associated with de novo or acquired tumor resistance in breast cancer, which compromises the therapeutic efficacy of the treatment, and CISC are widely considered to be the cell type responsible for recurrence of the metastatic cancer phenotype (1-4,9). Previous studies have demonstrated that small molecule inhibitors selective for the Wnt/ $\beta$-catenin signaling pathway preferentially inhibit the growth of breast CISC by inhibiting the binding of $\beta$-catenin to $\mathrm{T}$ cell factor and downregulating the insulin-like growth factor-1 signaling pathway (27). Therefore, further studies on stem cell-specific mechanistic pathways, including the Wnt/ $\beta$-catenin, notch and hedgehog signaling pathways, may aid in the identification of novel therapeutic targets for the treatment of breast cancer $(2,3,27-29)$.

In conclusion, future studies that employ reliable assays for the isolation and characterization of CISC and focus on the biology of cancer stem cells (particularly the molecular, genetic and endocrine mechanisms responsible for the survival of CISC), should collectively represent valuable approaches for identifying novel stem cell-targeted therapeutic options for the treatment of breast cancer.

\section{Acknowledgements}

The present study was funded by the National Cancer Institute (Bethesda, MD, USA; grants/contracts nos. CA-44741, CA-29502 and CN-75029-63) and the Department of Defense (Fort Detrick, MD, USA; grant no. DAMD17-94-J-4208). The author would like to acknowledge former colleagues Dr Meena Katdare, Dr Dan Sepkovic, Dr H. Leon Bradlow, Dr George Y.C. Wong and Dr Michael P. Osborne, for their active collaborations.

\section{References}

1. Stingl $\mathrm{J}$ and Caldas C: Molecular heterogeneity of breast carcinomas and the cancer stem cell hypothesis. Nat Rev Cancer 7: 791-799, 2007.

2. Dean M, Fojo T and Bates S: Tumour stem cells and drug resistance. Nat Rev Cancer 5: 275-284, 2005.

3. Lobo NA, Shimono Y, Qian D and Clarke MF: The biology of cancer stem cells Annu Rev Cell Dev Biol 23: 675-699, 2007.

4. Patel SA, Ndabahaliye A, Lim PK, Milton R and Rameshwar P: Challenges in the development of future treatments for breast cancer stem cells. Breast Cancer (Dove Med Press) 2: 1-11, 2010.

5. Sørlie T, Perou CM, Tibshirani R, et al: Gene expression patterns of breast carcinomas distinguish tumor subclasses with clinical implications. Proc Natl Acad Sci USA 98: 10869-10874, 2001.

6. Veronesi U, De Palo G, Costa A, Formelli F, Marubini E and Del Vecchio M: Chemoprevention of breast cancer with retinoids. J Natl Cancer Inst Monogr 12: 93-97, 1992. 
7. Fisher B, Costantino JP, Wickerham DL, Redmond CK, Kavanah M, Cronin WM, Vogel V, Robidoux A, Dimitrov N, Atkins J, et al: Tamoxifen for prevention of breast cancer: Report of the National Surgical Adjuvant Breast and Bowel Project P-1 Study. J Natl Cancer Inst 90: 1371-1388, 1998.

8. Cleator S, Heller W and Coombes RC: Triple-negative breast cancer: Therapeutic options. Lancet Oncol 8: 235-244, 2007.

9. Musgrove EA and Sutherland RL: Biological determinants of endocrine resistance in breast cancer. Nat Rev Cancer 9: 631-643, 2009.

10. Tanei T, Morimoto K, Shimazu K, Kim SJ, Tanji Y, Taguchi T, Tamaki Y and Noguchi S: Association of breast cancer stem cells identified by aldehyde dehydrogenase 1 expression with resistance to sequential Paclitaxel and epirubicin-based chemotherapy for breast cancers. Clin Cancer Res 15: 4234-4241, 2009

11. Van Phuc P, Nhan PL, Nhung TH, Tam NT, Hoang NM, Tue VG, Thuy DT and Ngoc PK: Downregulation of CD44 reduces doxorubicin resistance of CD44CD24 breast cancer cells. Onco Targets Ther 4: 71-78, 2011.

12. Zhang F. Song C, Ma Y, Tang L, Xu Y and Wang H: Effect of fibroblasts on breast cancer cell mammosphere formation and regulation of stem cell-related gene expression. Int J Mol Med 28: 365-371, 2011.

13. Suto A, Bradlow HL, Kubota T, Kitajima M, Wong GY Osborne MP and Telang NT: Alteration in proliferative and endocrine responsiveness of human mammary carcinoma cells by prototypic tumor-suppressing agents. Steroids 58: 215-219, 1993.

14. Telang NT, Katdare M, Bradlow HL, Osborne MP and Fishman J: Inhibition of proliferation and modulation of estradiol metabolism: Novel mechanisms for breast cancer prevention by the phytochemical indole-3-carbinol. Proc Soc Exp Biol Med 216: 246-252, 1997.

15. Jinno H, Steiner MG, Nason-Burchenal K, Osborne MP and Telang NT: Preventive efficacy of receptor class selective retinoids on HER-2/neu oncogene expressing preneoplastic human mammary epithelial cells. Int J Oncol 21: 127-134, 2002.

16. Mukherjee B, Telang N and Wong GYC: Growth inhibition of estrogen receptor positive human breast cancer cells by Taheebo from the inner bark of Tabebuia avellandae tree. Int J Mol Med 24: 253-260, 2009.

17. Telang $\mathrm{N}$ and Katdare M: Epithelial cell culture models for the prevention and therapy of clinical breast cancer (Review). Oncol Lett 3: 744-750, 2012.
18. Telang N, Li G, Sepkovic D, Bradlow HL and Wong GY: Comparative efficacy of extracts from Lycium barbarum bark and fruit on estrogen receptor positive human mammary carcinoma MCF-7 cells. Nutr Cancer 66: 278-284, 2014

19. Telang N: Cellular metabolism of estradiol in models for select molecular subtypes of clinical breast cancer. J Steroids Hormon Sci 5: 1-5, 2014.

20. Telang NT, Li G, Sepkovic DW, Bradlow HL and Wong GY Anti-proliferative effects of Chinese herb Cornus officinalis in a cell culture model for estrogen receptor-positive clinical breast cancer. Mol Med Rep 5: 22-28, 2012.

21. National Comprehensive Cancer Network: NCCN Clinical practice guidelines in oncology: Breast Cancer 1: 2010. http://www.ncen.org, 2010. Accessed July 5, 2011.

22. Johnston SRD and Dowsett M: Aromatase inhibitors for breast cancer: Lessons from the laboratory. Nat Rev Cancer 3: 821-831, 2003

23. Baselga J and Swain SM: Novel anticancer targets: Revisiting ERBB2 and discovering ERBB3. Nat Rev Cancer 9: 463-475, 2009.

24. Romond EH, Perez EA, Bryant J, Suman VJ, Geyer CE Jr, Davidson NE, Tan-Chiu E, Martino S, Paik S, Kaufman PA, et al: Trastuzumab plus adjuvant chemotherapy for operable HER-2-positive breast cancer. N Engl J Med 353 1673-1684, 2005.

25. Ibrahim YH, García-García C, Serra V, He L, Torres-Lockhart K, Prat A, Anton P, Cozar P, Guzmán M, Grueso J, et al: PI3K inhibition impairs BRCA1/2 expression and sensitizes BRCA-proficient triple-negative breast cancer to PARP inhibition. Cancer Discov 2: 1036-1047, 2012.

26. Martin HL, Smith L and Tomlinson DC: Multidrug-resistant breast cancer: Current perspectives. Breast Cancer (Dove Med Press) 6: 1-13, 2014

27. Hoffmeyer K, Raggioli A, Rudloff S, Anton R, Hierholzer A, Del Valle I, Hein K, Vogt R and Kemler R: Wnt/ $\beta$-catenin signaling regulates telomerase in stem cells and cancer cells. Science 336: 1549-1554, 2012.

28. Anastas JN and Moon RT: WNT signalling pathways as therapeutic targets in cancer. Nat Rev Cancer 13: 11-26, 2013.

29. Jang GB, Hong IS, Kim RJ, Lee SY, Park SJ, Lee ES, Park JH, Yun $\mathrm{CH}$, Chung JU, Lee KJ, et al: Wnt/ $\beta$-catenin small molecule inhibitor CWP232228 preferentially inhibits the growth of breast cancer stem-like cells. Cancer Res 75: 1961-1702, 2015. 